DOI 10. 18307/2017. 0301

(c) 2017 by Journal of Lake Sciences

\title{
拟建鄱阳湖水利枢纽工程对长江干流流量影响的模拟
}

\author{
赖格英 ${ }^{1,2}$, 张志勇 ${ }^{3}$, 王 鹏 ${ }^{1,2}$, 吴 青 $^{2}$, 潘思怡 ${ }^{2}$, 胡兴兴 ${ }^{2}$, 陈桃金 ${ }^{2}$ \\ ( 1 : 鄱阳湖湿地与流域研究教育部重点实验室, 南昌 330022) \\ ( 2 : 江西师范大学地理与环境学院, 南昌 330022$)$ \\ ( 3 : 江西省赣州市气象局,贑州 341000$)$
}

\begin{abstract}
摘 要: 维系江湖关系的重要基础是江湖之间的物质通量,而江湖之间物质通量的核心内容是水的通量. 规划中的鄱阳 湖水利枢纽工程, 以“一湖清水”为建设目标, 坚持“江湖两利” 的原则, 按“调枯不控洪”方式运行. 目前, 国内学者对拟建 的鄱阳湖水利枢纽工程可能导致湖泊影响方面的研究较多, 但对该工程能否实现或维持 “江湖两利”方面的研究较少. 本 文采用二维水动力模型, 针对拟建的鄱阳湖水利枢纽工程和规划中的水位调度方案, 分别从湖泊丰水期和枯水期两个时 段,选择鄱阳湖丰、平、枯 3 种典型年型, 在无枢纽与有枢纽两种情景模拟的基础上, 定量分析丰、平、枯 3 种典型年枢纽工 程的水位调度方案对长江干流流量的可能影响. 模拟结果表明: 在一个鄱阳湖水利枢纽工程水位调度周期中, 无枢纽状 态与有枢纽情景下湖泊外排到长江干流的径流总量差异很小, 从模拟的年份来看, 有枢纽外排减少量在 $0.2 \% \sim 0.7 \%$ 之间 变化, 基本维持了有枢纽与无枢纽状态下的水量平衡, 但在一定程度上改变了湖泊外排长江干流水量的分配时间, 使不 同年型丰水期的湖泊外排水量有所减少, 而在湖泊和长江低枯水期, 对长江流量则有一定的增排作用, 且增排效果为枯 水年型>平水年型>丰水年型, 不同年型的增排比例在 $2.1 \% \sim 17.0 \%$ 之间变化; 在丰水期湖泊水位偏低,且枢纽位置的实际 水位严重不足 $9 \mathrm{~m}$ 的年型情况下, 按照枢纽工程的水位调度方案要在 9 月 15 日将湖泊水位提升至 $14 \sim 15 \mathrm{~m}$ 是难于实现 的,现有的枢纽工程调度方案在这种情况下缺乏可操作性,有进一步细化和优化的空间.
\end{abstract}

关键词: 鄱阳湖; 水利枢纽工程; 长江; 流量; 数值模拟

\section{Simulation of impacts of Poyang Lake Hydraulic Project on the flow of the Yangtze River using an EFDC model}

\author{
LAI Geying ${ }^{1,2}$, Zhang Zhiyong ${ }^{3}$, WANG Peng ${ }^{1,2}$, WU Qing ${ }^{2}$, PAN Siyi ${ }^{2}$, HU Xingxing ${ }^{2}$ \& CHEN Taojin ${ }^{2}$ \\ ( 1: Key Laboratory of Poyang Lake Wetland and Watershed Research, Ministry of Education, Jiangxi Normal University, Nan- \\ chang 330022, P.R.China) \\ (2: School of Geography and Environment, Jiangxi Normal University, Nanchang 330022, P.R.China) \\ (3: Ganzhou Meteorological Bureau of Jiangxi Province, Ganzhou 341000, P.R.China)
}

Abstract: Mass flux is an important basis for maintaining the relationship between lakes and rivers, while the key of mass flux is
water flux. Aiming to a goal of constructing a clear water that are conducive to both the Yangtze River and Poyang Lake, the Poyang
Lake Hydraulic Project ( PLHP) in planning will be operated according to a proposed water level regulating scheme in the view of
ecology, in which is controlling over the lake level in the dry season instead of the wet season. By using two-dimensional hydrody-
namic model, this paper conducts a quantitative analysis concerning the potential impacts of the water level regulating scheme of
PLHP under three typical hydro-years ( wet, normal and dry years) on stream flow of the Yangtze River. According to the simula-
tion results, during a PLHP water level regulating period, the difference, the discharge from the lake to the Yangtze River is very
small, only varied from $-0.2 \%$ to - $0.7 \%$ compared with two modeling scenarios ( with or without the PLHP). The discharge under
those two scenarios is basically maintained in a balanced state, though the seasonal distribution time from the lake to the Yangtze
River is changed. During the dry season, the project has minor impact on the flow of the Yangtze River, or even increases the a-

* 国家重点基础研究发展计划“973”项目(2012CB417003)、江西省重大生态安全问题监控协同创新中心项目 (JXSEW-00) 和国家自然科学基金项目 (41561101) 联合资助. 2016-06-12 收稿; 2016-08-31 收修改稿. 赖格英 (1963 ), 男,博士, 教授;E-mail: laigeying@126.com. 
mount of water discharges. The dry year has a maximum effect of the increased discharge, followed by normal year and the third by wet year. The increased discharge in different hydro-years varies from $2.1 \%$ to $17.0 \%$. In normal year and dry year, the lake level before the beginning of the PLHP regulation is much lower than the highest regulated water level of $9 \mathrm{~m}$, so that the existing PLHP regulation scheme, which proposes to regulate the water level to $14-15 \mathrm{~m}$ on September 15 , has obvious defects and need a further optimization.

Keywords: Poyang Lake; hydraulic project; the Yangtze River; discharge; numerical simulation

江湖关系是自然与人文驱动力长期相互作用和相互适应的结果, 江湖之间的能量流、物质流和生物流 相互交织,构成了复杂的江湖关系. 维系江湖关系的重要基础是江湖之间的物质通量, 而江湖之间物质通量 的核心内容是水的通量. 鄱阳湖是我国最大的淡水湖, 是长江水系中的两大通江湖泊之一, 具有调蓄洪水和 保护生物多样性等特殊生态功能,对维持区域和国家的生态安全具有重要作用. 规划中的鄱阳湖水利枢纽 工程,虽然坚持 “江湖两利” 的理念, 按“调枯不控洪” 方式运行, 但该工程的建设客观上会对长江中下游的 水文情势带来一定程度的影响, 从而打破原有的江湖平衡关系, 引发江湖关系的新变化. 因此, 如何定量评 估鄱阳湖水利枢纽工程对长江干流流量的影响仍是十分重要的研究课题.

目前国内学者就拟建的鄱阳湖水利枢纽工程对湖泊水文、水质和生态等多方面进行过较多的定性或定 量研究, 如余启辉等 ${ }^{[1]}$ 采用江湖连通一、二维耦合水文-水动力模型的数值模拟研究结果表明: 鄱阳湖水利 枢纽工程的调度方案对湖区星子、都昌、吴城和康山各断面枯水期水位有所抬升, 星子、都昌、吴城和棠荫各 断面流速均有所减小,但影响主要集中在星子至都昌一带 (松门山以北区域); 王鹏等 ${ }^{[2-3]}$ 和赖格英等 ${ }^{[4-5]}$ 以 二维水动力模型为基础模拟了无枢纽及有枢纽两种情景下湖泊的水动力场, 探讨了鄱阳湖水利枢纽工程运 行后对主湖区及鄱阳湖两大自然保护区水位变化的时间节律影响、不同情景年型下鄱阳湖水利枢纽工程调 度方案的低枯水期 $11 \mathrm{~m}$ 最低调度水位对主湖区不同空间位置水位的抬升程度, 并分析了鄱阳湖水利枢纽 工程对湖泊流场和湖泊换水周期的可能影响,得出的主要结论为: 枢纽工程调度水位的 $11 \mathrm{~m}$ 最低调度水位 使丰、平、枯三种年型下湖泊平均水位的最大抬升在 $2.59 \sim 4.35 \mathrm{~m}$ 间变化, 同时枢纽工程的水位调度使不同 年型的换水周期受到不同程度的影响, 枯水年型影响最大, 影响程度达 $26.1 \%$; 杜彦良等 ${ }^{[6-7]}$ 采用二维水动力 水质模型对鄱阳湖水动力和水质进行了模拟,在现有外部人流边界和污染负荷条件下以枢纽工程的 3 种调 度方案分析了鄱阳湖湖流的时空形态变化和相应的水质变化,结果表明: 枢纽工程使枯水期大部分湖区的 水质浓度下降, 但尾问等部分区域有所升高, 开闸泄水期前后, 水质较现状水质下降,敞泄期的大部分时间, 较现状水质基本相似, 蓄水期水质变化不大. 在枢纽工程对长江干流可能造成的影响研究方面, 张双虎等 ${ }^{[8]}$ 通过预设不同的枢纽调度方案对有枢纽及无枢纽条件下的出湖流量进行估算, 分析了鄱阳湖蓄水期、三峡 水库蓄水期和鄱阳湖枯水期的流量差异, 并对枢纽工程对长江干流的防洪影响进行了分析, 认为枢纽建设 可基本解决湖区枯水期缺水问题, 如采用合理的运行调度方式, 对长江下游水资源利用没有明显影响, 并在 一定程度上可补偿三峡及以上水库蓄水期对长江下游的影响; 谭国良等 ${ }^{[9]}$ 采用水文学中的设计频率法、水 量平衡法、河道流量演算法及典型年法等常规方法, 估算了水位调度方案中不同时期 3 种设计频率下枢纽 工程对长江干流流量的影响, 结果表明枢纽工程对长江干流可以起到一定的增补水量的作用. 因此, 从目前 国内研究现状来看, 对拟建的鄱阳湖水利枢纽工程可能导致湖泊影响方面的研究较多, 但对该工程可能造 成长江干流的影响研究则相对较少, 且研究方法采用的多半是统计估算.

本文采用二维水动力模型, 针对拟建的鄱阳湖水利枢纽工程和规划中的水位调度方案, 分别从湖泊丰 水期和枯水期两个时段,采用皮尔逊 III型的水文频率分析方法,选择鄱阳湖丰、平、枯 3 种典型年型,在无枢 纽与有枢纽两种情景模拟的基础上, 定量分析典型年型枢纽工程水位调度方案对长江干流流量的可能影 响, 为进一步研究鄱阳湖水利枢纽工程的生态效应及对长江中下游带来的影响提供必要的支撑.

\section{1 研究区概况}

\section{1 鄱阳湖及其与长江干流的关系}

鄱阳湖 $\left(28^{\circ} 22^{\prime} \sim 29^{\circ} 45^{\prime} \mathrm{N}, 115^{\circ} 47^{\prime} \sim 116^{\circ} 45^{\prime} \mathrm{E}\right)$ 是中国第一大淡水湖, 地处江西省北部, 长江中下游南岸. 鄱阳湖以松门山为界, 分为南北两部分, 北面为人江水道, 长 $40 \mathrm{~km}$, 宽 $3 \sim 5 \mathrm{~km}$, 最窄处约 $2.8 \mathrm{~km}$; 南面为主 
湖体, 长 $133 \mathrm{~km}$, 最宽处达 $74 \mathrm{~km}$. 湖泊承纳流域的赣江、抚河、修河、信江和饶河五河来水, 经湖口注人长江. 鄱阳湖受五河来水及长江水情的影响,湖泊水位呈现高动态的季节变化. 从 1950-2012 年间 6-9 月丰水 期的湖口最高水位可达 $20.59 \mathrm{~m}$ (黄海高程, 下同), 枯水期水位最低至 $5.90 \mathrm{~m}$, 鄱阳湖各水文站多年最高最 低水位差为 $10.34 \sim 16.69 \mathrm{~m}$. 受长江来水影响, 鄱阳湖在长江高水位期间, 湖泊会出现倒灌和顶托等湖流形 态 ${ }^{[9]}$. 从多年平均来看, 鄱阳湖经湖口的出流量占长江大通水文站 (图 1) 流量的比例各月在 $9.72 \% \sim 29.03 \%$ 之 间变化,占比最小值出现在 9 月, 占比最大值出现在 4 月. 一般地, 在 3-6 月期间鄱阳湖的水文水动力特性主 要受流域来水影响较大, 而在 7-11 月期间主要受长江的水情影响较大 ${ }^{[9-11]}$. 此外, 本文通过长江大通水文站 1960-2014 年共 55 年的流量资料分析表明,长江中游的低枯水期一般在 1-3 月和 12 月,丰水期一般在 6-9 月,其余月份为长江的平水期,这与文献 $[11]$ 的划分一致 ${ }^{[11]}$.

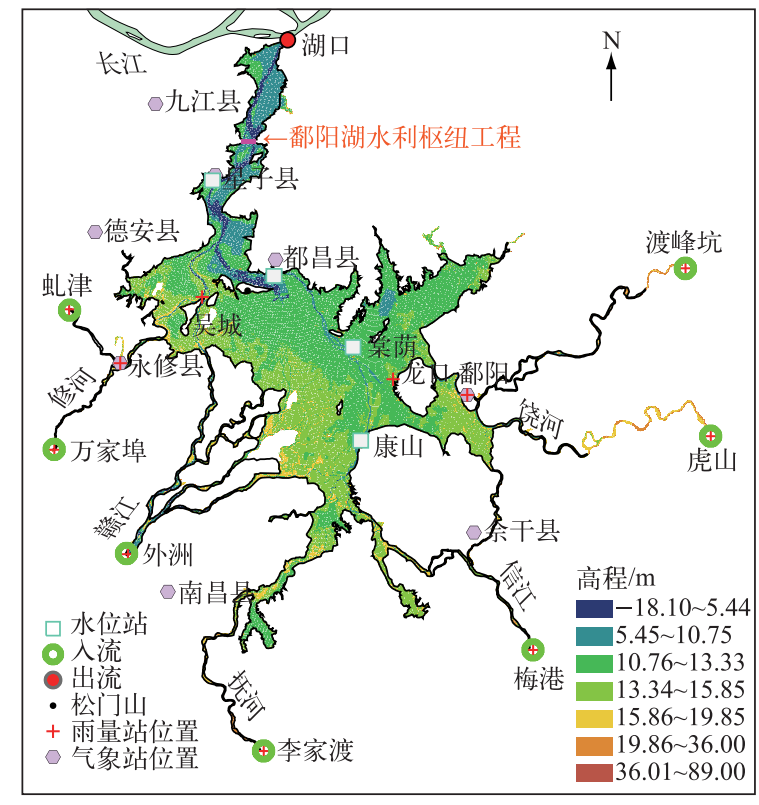

图 1 鄱阳湖地图及相关水文站、气象站分布

Fig. 1 The map of Poyang Lake and the distribution of hydrologic/weather stations

\section{2 鄱阳湖水利枢纽工程及其调度方案}

按江西省水利厅发布的建设方案, 拟建的鄱阳湖水利枢纽工程坝址选定于鄱阳湖人江水道 $\left(29^{\circ} 32^{\prime} \mathrm{N}\right.$, $116^{\circ} 07^{\prime} \mathrm{E}$ ), 介于庐山区长岭与湖口县屏峰山之间, 两山之间湖面宽约 $2.8 \mathrm{~km}$, 为鄱阳湖人长江通道最窄之 处,该处上距星子县城约 $12 \mathrm{~km}$,下至长江汇合口约 $27 \mathrm{~km}$. 该工程以“一湖清水”为建设目标, 坚持“江湖两 利” 的原则, 按“调枯不控洪” 方式运行, 与三峡水库运行方式相协调, 实行错时蓄水和腾空, 按生态保护和综 合利用要求控制相对稳定的鄱阳湖枯水位, 提高鄱阳湖枯水季节水环境容量, 达到保护水生态水环境、从根 本解决湖区干旱及生态缺水问题、改善湿地环境、消灭钉螺、提高航道等级、发展湖区旅游及渔业等方面的 综合效益. 表 1 给出了规划中的鄱阳湖水利枢纽工程最新水位调度方案.

\section{2 模型的建立与验证}

\section{1 数值模型}

鄱阳湖水动力模型以 EFDC (Environmental Fluid Dynamics Code-EFDC) 模型为基础水动力模型. EFDC 是由威廉玛丽大学维吉尼亚海洋科学研究所 (VIMS, Virginia Institute of Marine Science at the College of William and Mary) Hamrick 等开发的综合模型 ${ }^{[12]}$, 可实现河流、湖泊、水库、湿地系统、河口和海洋等水体的 
表 1 鄱阳湖水利枢纽工程规划调度方案 (1)

Tab.1 The regulation schemes of water level for the Poyang Lake Hydraulic Project

\begin{tabular}{|c|c|c|}
\hline 调度时段 & 时间 & 江湖连通状态及调度方案 \\
\hline 江湖连通期 & 3 月 15 日 -8 月 31 日 & 闸门全开, 江湖连通; 江湖间水流、能量、生物自由交换. (类似于天然状况) \\
\hline 枢纽蓄水期 & 9 月 1 日 -9 月 15 日 & $\begin{array}{l}9 \text { 月 } 1 \text { 日 }-9 \text { 月 } 15 \text { 日,利用长江高水位期间,鄱阳湖洪水尾巴下闸节制湖水 } \\
\text { 位,至 } 15 \text { 日水位一般控制在 } 14 \sim 15 \mathrm{~m} \text { (黄海高程,下同). }\end{array}$ \\
\hline 三峡水库蓄水期 & 9 月 16 日一 10 月 31 日 & $\begin{array}{l}9 \text { 月 } 16 \text { 日 }-10 \text { 月 } 10 \text { 日, 综合考虑湖区灌溉和生态需求, 湖水位渐降至 } 12 \mathrm{~m} \text {; } \\
10 \text { 月 } 11 \text { 日- } 10 \text { 月 } 31 \text { 日,水位由 } 12 \mathrm{~m} \text { 降至 } 11 \mathrm{~m} .\end{array}$ \\
\hline 补偿调节期 & 11 月 1 日一 1 月 10 日 & 11 月 1 日 -1 月 10 日,水位在 $11 \mathrm{~m}$ 波动; \\
\hline 低枯水期 & 1 月 11 日 -3 月 10 日 & $\begin{array}{l}1 \text { 月 } 11 \text { 日-2 月 } 10 \text { 日,湖区水位由 } 11 \mathrm{~m} \text { 降至 } 10 \mathrm{~m} \text {; } \\
2 \text { 月 } 11 \text { 日 }-3 \text { 月 } 10 \text { 日,湖水位节制在 } 10 \sim 11 \mathrm{~m} \text { 之间; } \\
3 \text { 月 } 11 \text { 日起,视长江、鄱阳湖来水情况逐渐调至天然状态 (防止水位骤降), } \\
\text { 当来水量较大时,闸门合开. }\end{array}$ \\
\hline
\end{tabular}

一维至三维水动力、泥沙淤积与水质模拟. 该模型在水平方向采用直角坐标或正交曲线坐标, 垂直方向采用 $\sigma$ 坐标. 动力学方程采用有限差分法求解, 水平方向采用交错网格离散, 时间积分采用二阶精度的有限差分 法以及内外模式分裂技术 (即采用剪切应力或斜压力的内部模块和自由表面重力波或正压力的外模块分开 计算). 外模块采用半隐式计算方法,允许较大的时间步长,且可采用自适应时间步长模式. 内模块采用了垂 直扩散的隐式格式, 期间水陆漫滩带区域采用了动边界干湿格网判别技术. 此外, 该模型由 Fortran 语言开发 而成,源代码开放,易于根据不同的应用目标进行适当的修改,有较大的适用性.

\section{2 模型的构建及边界条件}

鄱阳湖是一个浅水湖泊, 胡春华等 ${ }^{[13]}$ 认为可以采用二维的水动力模型来模拟湖泊的水文、水动力及水 质的问题. 因此, 本文在 EFDC 水动力模型基础上,建立了鄱阳湖的二维水动力模型, 该模型以 1998 年鄱阳 湖洪水期间的遥感影像为参照, 结合鄱阳湖圩堤 GIS 数据, 确定湖泊最大水面范围作为模型的计算域. 采用 正交曲线格网对计算域进行了格网化; 格网总数为 96004 , 格网分辨率介于 $178 \sim 205 \mathrm{~m}$ 之间, 格网的正交性 参数小于 0.2 (图 2). 由于格网为非正方形格网, 其长宽不等, 故格网分辨率参数是用每个格网面积的平方 根来表示的. 在构建计算格网时, 在一定程度上考虑了湖盆地形的高程变差, 从图 $2 \mathrm{~b}$ 可以看出, 在湖泊北部 和东部, 由于高程变差较大, 采用了较小的格网来反映地形高程变差, 而在高程变差小的湖泊漫滩部分 (湖 泊中部)采用了较大的格网, 以控制格网总数,减小计算耗时.

鄱阳湖水底地形采用的是 2010 年的实测数据,其比例尺为 $1: 10^{4}$, 由江西省水利厅提供. 模型的上边界 为鄱阳湖虬津、万家埠、外洲、李家渡、梅港、虎山、渡峰坑等五河七口的实测逐日流量数据,下边界为湖口的 逐日实测水位数据. 由于鄱阳湖人湖流量除赣江、抚河、修河、信江和绕河的五河来水外, 尚有部分湖区的来 水未纳人考虑, 且这些区域并非水文意义上的完整流域, 水量无法通过常规的水文观测得到 ${ }^{[8]}$. 因此, 为了 保持人流与出流的水量平衡, 在模拟过程中, 将人流流量数据乘了一个比例系数, 使在一个模拟的水文周期 中, 人流量大致等于出流量; 此外, 鄱阳湖的地下水仅占湖泊总水量的 $1.3 \%^{[14]}$, 且湖区地下水的观测数据相 对较少, 为此, 在模型构建与模拟过程中, 没有考虑地下水问题.

模型的气象边界条件包括渡峰坑、虎山、虬津、吴城、永修、李家渡、外洲、万家埠、都昌、康山、棠荫、龙 口、星子、梅港和鄱阳等 15 个雨量站逐日降雨数据, 鄱阳县、都昌县、星子县、南昌县、九江县、永修县、德安 县、余干县等 9 个县气象站的风速、风向、气温、气压、相对湿度、干球与湿球温度、云量等逐日数据.

\section{3 模型的率定与验证}

模型的参数率定是非常耗时的, 考虑到模拟耗时问题, 模型的率定时段选取 2000 年 1 月 1 日 -2000 年 7 月 31 日之间的 7 个月, 该时段包含丰水期和枯水期. 模拟的时间步长采用自适应时间步长模式, 自适应时 间步长的基本增量为 $1 \mathrm{~s}$. 表 2 列出了模型主要参数的率定结果, 其中格网干深、格网湿深和干湿判断的时间

(1) 资料来源: 2013 年 9 月 17 日由江西省水利厅发布. 

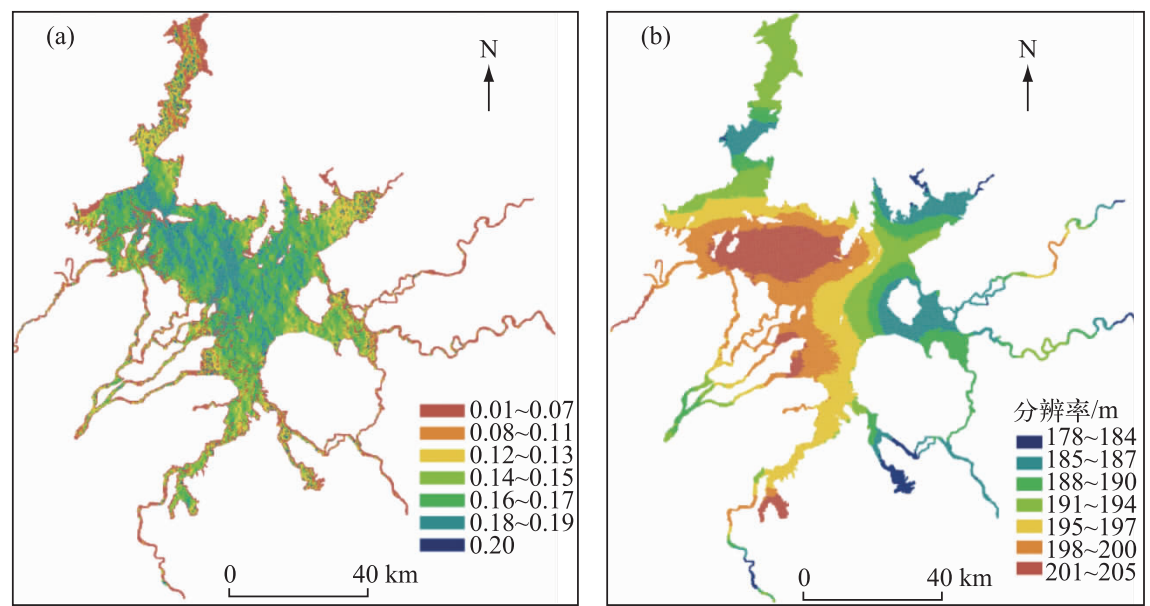

图 2 鄱阳湖水动力模型的格网的正交性 ( a ) 和格网分辨率 $(\mathrm{b})$

Fig.2 Orthogonality (a) and resolution (b) of grid in the Poyang Lake hydrodynamic model

步长是模型运行过程中涉及的水陆漫滩区域运动边界干湿格网判断技术中的参数, 格网干深和格网湿深分 别是水陆漫滩区域格网由湿变干和由干变湿的水深阈值.

表 2 模型主要参数的率定结果

Tab.2 Calibrated parameters and optimal values

\begin{tabular}{lccc}
\hline 参数 & 初始值 & 范围 & 率定结果 \\
\hline 湖底䊁度 $/ \mathrm{m}$ & 0.2 & $0.01 \sim 0.40$ & 河槽: 0.2 ; 漫滩区: 0.25 \\
水平涡流粘度 $/\left(\mathrm{m}^{2} / \mathrm{s}\right)$ & 0.1 & $0.01 \sim 0.40$ & 0.25 \\
格网湿深 $/ \mathrm{m}$ & 0.1 & $0.01 \sim 0.20$ & 0.06 \\
格网干深 $/ \mathrm{m}$ & 0.1 & $0.01 \sim 0.20$ & 0.09 \\
干湿判断的时间步长 $/ \mathrm{s}$ & 12 & $10 \sim 30$ & 16 \\
\hline
\end{tabular}

模型的验证时期为 2001 年 1 月 1 日一-2005 年 12 月 31 日,共 5 年时间. 分别选取鄱阳湖南北方向不同 部位的星子、都昌、棠荫和康山 4 个站点的实测水位对模拟水位加以验证, 流量则选取鄱阳湖的湖口实测流 量来验证. 参数率定以后 2001 年 1 月 1 日 -2005 年 12 月 31 日 4 个验证站点的实测水位与模拟水位和实测 流量与模拟流量的对照见图 3. 由于论文篇幅所限,流速的验证请参考文献[3].

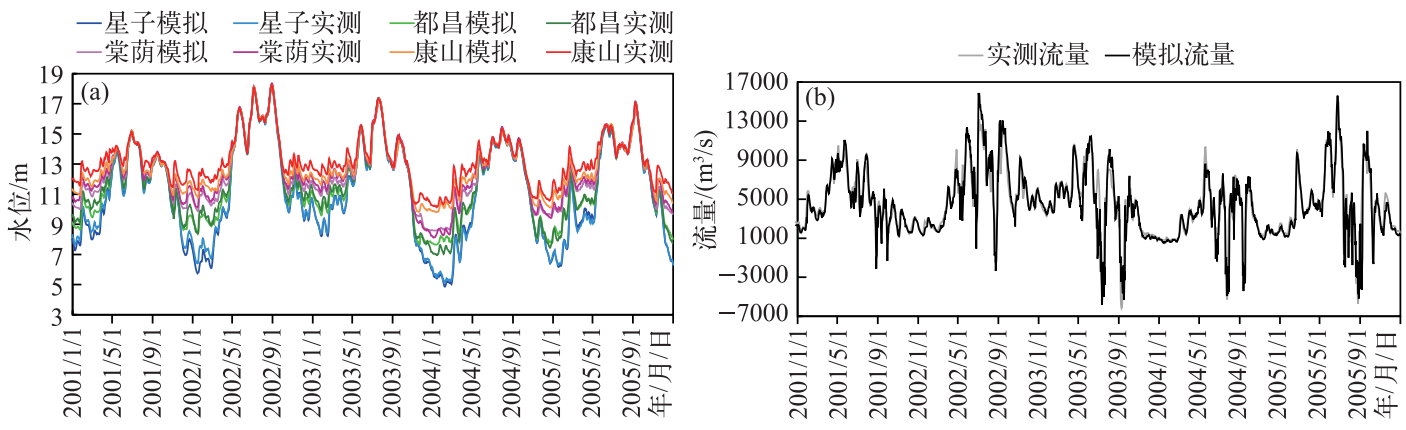

图 3 实测水位与模拟水位 (a) 和实测流量与模拟流量 $(b)$ 对照

Fig.3 Measured/simulated water level (a) and flow (b) 
率定时期 4 个验证点的水位平均绝对误差在 $0.278 \sim 0.560 \mathrm{~m}$ 之间, 平均相对误差在 $2.510 \% \sim 4.475 \%$ 之 间,均方根误差 (RMSE 误差) 在 $0.371 \sim 0.635$ 之间,纳西 ( Nash-Stucliffe) 效率系数 ${ }^{[15]}$ 在 $0.808 \sim 0.981$ 之间; 而验证时期 4 个验证点的水位平均绝对误差在 $0.166 \sim 0.411 \mathrm{~m}$ 之间, 平均相对误差在 $1.823 \% \sim 3.269 \%$ 之 间, RMSE 误差在 $0.249 \sim 0.505$ 之间, 纳西效率系数在 $0.895 \sim 0.993$ 之间. 观测最大值与模拟最大值、观测最 小值与模拟最小值是同步的 (表 3 ).

\section{表 3 模拟的水位误差分析}

Tab.3 Error analysis for simulated water levels

\begin{tabular}{|c|c|c|c|c|c|c|c|c|}
\hline \multirow{2}{*}{ 误差分析指标 } & \multicolumn{4}{|c|}{ 率定误差 } & \multicolumn{4}{|c|}{ 验证误差 } \\
\hline & 星子 & 都昌 & 棠荫 & 康山 & 星子 & 都昌 & 棠荫 & 康山 \\
\hline 观测最大值/m & 16.150 & 16.120 & 16.200 & 16.070 & 18.200 & 18.280 & 18.370 & 18.260 \\
\hline 模拟最大值/m & 16.109 & 16.133 & 16.120 & 16.125 & 18.200 & 18.240 & 18.200 & 18.250 \\
\hline 观测最小值/m & 6.630 & 8.000 & 9.800 & 11.000 & 5.150 & 6.960 & 8.130 & 10.150 \\
\hline 模拟最小值/m & 6.160 & 8.085 & 9.680 & 10.430 & 4.860 & 7.650 & 8.590 & 9.810 \\
\hline 平均绝对误差 $/ \mathrm{m}$ & 0.281 & 0.278 & 0.290 & 0.560 & 0.166 & 0.216 & 0.236 & 0.411 \\
\hline 平均相对误差/\% & 3.421 & 2.696 & 2.510 & 4.475 & 1.823 & 2.091 & 1.987 & 3.269 \\
\hline RMSE 误差 & 0.411 & 0.378 & 0.371 & 0.635 & 0.249 & 0.295 & 0.305 & 0.505 \\
\hline 纳西效率系数 & 0.981 & 0.975 & 0.962 & 0.808 & 0.993 & 0.986 & 0.978 & 0.895 \\
\hline
\end{tabular}

流量在率定时期的平均相对误差为 $22.98 \%$, 纳西效率系数为 0.90 ,一致性指数为 0.97 ; 而验证时期的平 均相对误差为 $20.75 \%$, 纳西效率系数为 0.83 , 一致性指数 ${ }^{[15]}$ 为 0.96 . 率定时期的最大观测值与最大模拟值、 最小观测值与最小模拟值是同步的, 验证时期的最大观测值与最大模拟值也是同步的, 但最小观测值与最 小模拟值不同步 (表 4).

表 4 率定和验证时期的流量误差分析

Tab.4 Error analysis of flow for calibration and validation

\begin{tabular}{cccccccc}
\hline \multirow{2}{*}{ 类型 } & 值类型 & $\begin{array}{c}\text { 最大值/ } \\
\left(\mathrm{m}^{3} / \mathrm{s}\right)\end{array}$ & $\begin{array}{c}\text { 最小值/ } \\
\left(\mathrm{m}^{3} / \mathrm{s}\right)\end{array}$ & $\begin{array}{c}\text { 平均值/ } \\
\left(\mathrm{m}^{3} / \mathrm{s}\right)\end{array}$ & $\begin{array}{c}\text { 平均相对 } \\
\text { 误差/\% }\end{array}$ & $\begin{array}{c}\text { 纳西效 } \\
\text { 率系数 }\end{array}$ & $\begin{array}{c}\text { 一致性 } \\
\text { 指数 }\end{array}$ \\
\hline \multirow{2}{*}{ 率定 } & 实测值 & 12700 & -1500 & 4503 & 22.98 & 0.90 & 0.97 \\
& 模拟值 & 13305 & -2135 & 4103 & & & 0.96 \\
\multirow{3}{*}{ 验证 } & 实测值 & 13900 & -6160 & 4519 & 20.75 & 0.83 & \\
& 模拟值 & 15890 & -5825 & 4382 & & & \\
\hline
\end{tabular}

为了对比模拟与实际的水面差异,分别选取高、低水位时的 2000 年 9 月 23 日和 1999 年 12 月 10 日两 景遥感影像, 用于评估高、低水位条件下模拟结果的空间吻合度. 图 4a 和 4b 分别为 1999 年 12 月 10 日模拟 和遥感影像中的湖泊水面, 图 4c 和 $4 \mathrm{~d}$ 分别为 2000 年 9 月 23 日模拟和遥感影像中的湖泊水面. 空间吻合度 的评估方法采用遥感影像分类精度的常规评估方法, 其具体做法是先在研究区空间范围内随机产生 1000 个点, 然后检查这些点在实际水面与模拟水面的对应情况, 如果某点在模拟水面上对应的是水, 而在实际影 像上对应的不是水, 则模拟结果是错误的. 反之亦然. 模拟结果的空间吻合度即是模拟正确的随机点数与总 随机点数之间的百分比. 高水位时模拟的面积相对误差和空间吻合度分别为 $5.5 \%$ 和 $93.6 \%$, 而低枯水位时 这两个误差参数分别为 $10.4 \%$ 和 $85.8 \%$ (表 5 ), 表明高水位时的模拟效果比低枯水位时的好.

\section{3 模拟方法}

\section{1 典型水文年型的选择}

考虑到实测的鄱阳湖水底地形 DEM 的时效性, 典型水文年型主要在 2000-2013 年进行选择, 但简单地 以年为时间尺度来衡量水文年型势必掩盖枢纽工程不同调度阶段的水文特征. 为了更好地反映枢纽工程调 

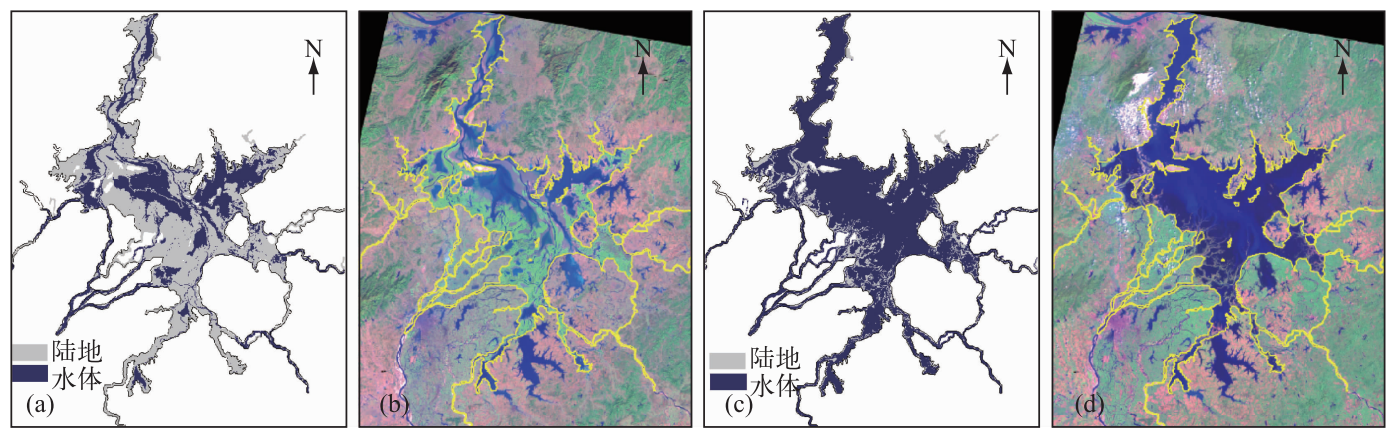

图 41999 年 12 月 10 日和 2000 年 9 月 23 日的模拟水面 $(a 、 c)$ 与遥感水面 $(b 、 d)$ 的对比

Fig.4 Comparison between simulated water surface ( a, c) and water surface in satellite image (b, d) on Dec. 10, 1999 and Sep. 23, 2000

表 5 模拟水面与实际水面的误差及其空间吻合度

Tab.5 Error between simulated water surface area and actual water surface area and their spatial matches

\begin{tabular}{cccccc}
\hline 水位状态 & 时间 & 模拟水面面积 $/ \mathrm{km}^{2}$ & 遥感解译面积 $/ \mathrm{km}^{2}$ & 面积的相对误差 $/ \%$ & 空间吻合度 $/ \%$ \\
\hline 高水位 & $2000-9-23$ & 2887.6 & 2728.3 & 5.5 & 93.6 \\
低枯水位 & $1999-12-10$ & 1016.1 & 1134.6 & 10.4 & 85.8 \\
\hline
\end{tabular}

度时期的水文特征,将该时期分为两个阶段:第一阶段为 9 月 1 日 - 10 月 31 日,以蓄排水为主要特征, 属于 枢纽工程调度时期的丰水期;第二阶段为 11 月 1 日至次年的 3 月 25 日,是水位的相对稳定时期,其水位基 本稳定在 10 11 m, 属于枢纽工程调度时期的枯水期. 对这两个阶段分别选取“丰、平、枯” 3 种年型.

通常水文年型是以流量来划分的, 但在顶托或倒灌情况下, 湖口会出现水位很高但流量偏小或负流量 的情况, 从而以流量为指标将无法正确反映湖泊的 “丰、平、枯” 3 种水文状态, 且枢纽工程调度方案的最高 调度水位为 $15 \mathrm{~m}$, 采用平均水位来划分水文年型, 同样难于反映 $14 \sim 15 \mathrm{~m}$ 最高调度水位的基本特征. 因此, 丰水期的“丰、平、枯” 3 种年型以 9-10月份的最高水位来划定,而枯水期的“丰、平、枯”水文年型则以 11 月 1 日至次年 3 月 25 日的湖口平均流量来确定. 由于枯水期跨两个年份,为方便计, 以起始年份作为该年型 的年份标记. 根据湖口 1950-2014 年共 65 年的水位和流量资料, 并利用 P-III曲线水文频率, 最后选定 2002 年、2009 年和 2006 年分别代表丰水期的丰水年型、平水年型和枯水年型, 而 2002 年、2001 年和 2003 年作 为枯水期的丰水年型、平水年型和枯水年型. 鄱阳湖水利枢纽工程水位调度时期丰水期及枯水期的典型年 份及其水文特征、P-III 水文频率见表 6 .

表 6 鄱阳湖水利枢纽工程水位调度时期丰水期及枯水期的典型年份及其水文特征

Tab.6 Typical year and hydrological characteristics in the wet and dry seasons in the water level regulation period of the Poyang Lake Hydraulic Project

\begin{tabular}{cccccccc}
\hline \multirow{2}{*}{ 年型 } & \multicolumn{3}{c}{ 枢纽工程主要调度时期的丰水期 } & & \multicolumn{3}{c}{ 枢纽工程主要调度时期的枯水期 } \\
\cline { 2 - 3 } & 年份 & 最高水位 $/ \mathrm{m}$ & $\mathrm{P}$-III水位频率 $/ \%$ & & 年份 & 平均流量 $/\left(\mathrm{m}^{3} / \mathrm{s}\right)$ & $\mathrm{P}$ - III 水位频率 $/ \%$ \\
\hline 丰水年 & 2002 & 18.01 & 9.2 & & 2002 & 5336 & 3.1 \\
平水年 & 2009 & 14.18 & 69.7 & & 2001 & 2519 & 52.5 \\
枯水年 & 2006 & 9.42 & 97.4 & & 2003 & 1418 & 91.2 \\
\hline
\end{tabular}

\section{2 模拟方案}

按本文 2.2 节所述的上边界、下边界和气象边界条件进行的模拟,作为无枢纽状态下的模拟; 将无枢纽 状态下的下边界换为枢纽工程边界条件, 其余边界条件不变, 按这种方式进行的模拟作为有枢纽的情景模 
拟. 枢纽工程边界条件设在鄱阳湖水利枢纽工程位置上 (图 1), 并定义为 “开放型边界” 类型的水位强迫; 其 水位由枢纽工程水位调度方案来确定,其基本规则是: 1 ) 江湖连通时期,水位与无枢纽状态下的水位一致; 2) 水位调度期间如遇调度水位高于无枢纽状态下的水位, 则以调度水位为此时的水位, 否则以无枢纽状态 下的水位作为该期间的水位; 3) 按照现有的调度方案, 枢纽蓄水期的最高调度水位定为 $14 \sim 15 \mathrm{~m}$, 为了考虑 极端情况,在确定枢纽工程边界条件时,将枢纽蓄水期的最高调度水位定为 $15 \mathrm{~m}$.

\section{4 结果分析}

\section{1 丰水年型的影响}

在枢纽调度时期的丰水期和枯水期, 2002 年均是丰水年型. 在 4-8 月期间, 由于湖泊处于江湖联通状 态, 有枢纽与无枢纽情景的水位是一致的 (图 5a), 其他边界条件也基本相同,理论上来说该时段模拟的无枢 纽与有枢纽流量应该完全一致, 但模拟结果却表明该时期有枢纽与无枢纽状态下的外排流量并不一致 (图 $5 b)$. 表 7 也表明从 3 月 26 日 -8 月 31 日的整个江湖联通期, 有枢纽与无枢纽状态下的径流总量相对减少 $0.1 \%$; 其他年份的模拟结果在该时期都表现出相同的趋势. 因此, 本文将这期间有枢纽与无枢纽状态下的模 拟差异视为模拟的系统误差.

2002 年 9 月 1 日- 9 月 15 日,湖泊处于蓄水期,按照枢纽调度方案水位逐步抬升至 $15 \mathrm{~m}$. 由于实际水 位大于 $15 \mathrm{~m}$ 的调度水位 (图 5a), 因而该时期有枢纽与无枢纽状态下的径流总量差异不大, 其相对减少 $0.6 \%$ (表 7). 9 月 16 日-10月 31 日期间, 枢纽调度处于三峡水库蓄水期,枢纽的水位调度由 $15 \mathrm{~m}$ 逐渐下降 至 $12 \mathrm{~m}$. 三峡水库蓄水期的 9 月 16 日-10 月 10 日时段,有枢纽与无枢纽相比外排水量减少了 $8.9 \%$ (表 7 ), 约占长江大通径流总量的 $2.5 \%$; 而在 10 月 11 日至 10 月 31 日期间, 有枢纽与无枢纽相比外排水量增加 了 $20.1 \%$, 约占长江大通径流总量的 3.8\% (表 7) ; 但就整个三峡水库蓄水期而言, 外排总水量仍是减少的, 但减少量很小, 其值为 $0.7 \% .11$ 月 1 日 - 1 月 10 日, 枢纽调度处于补偿调节期, 湖泊水位维持在 $11 \mathrm{~m}$. 这一 过程中,有枢纽比无枢纽湖泊外排水量的相对减少 $2.1 \%$,其值很小 (表 7 ).
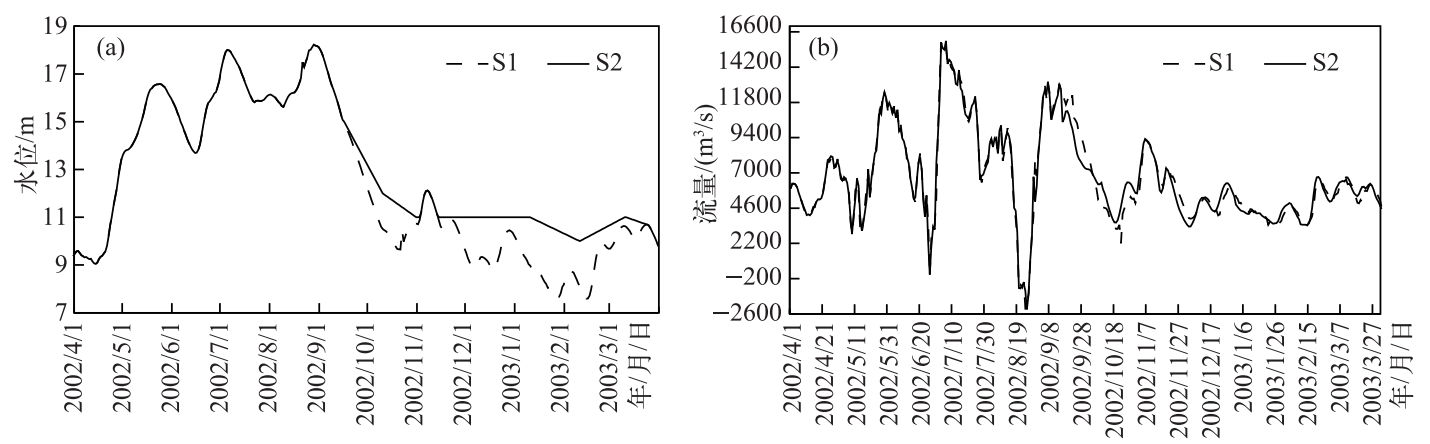

图 5 2002-2003 年无枢纽 (S1) 与有枢纽 (S2) 情景下的水位 (a) 和相应的逐日流量 (b)

Fig.5 Water levels (a) and flow hydrographs (b) of the lake in the scenarios with (S2) and without (S1) the Poyang Lake Hydraulic Project from 2002 to 2003

1 月 11 日- 3 月 25 日, 枢纽调度处于低枯水期, 调度水位经历由 $11 \mathrm{~m}$ 降至 $10 \mathrm{~m}$ 再升至 $11 \mathrm{~m}$ 然后向自 然状态水位过渡的 3 个变化过程 (表 1). 这 3 个过程有枢纽与无枢纽相比,外排径流总量分别增加 $2.4 \%$ 、 $1.3 \%$ 和 $2.9 \%$, 占长江大通同期径流总量的 $0.6 \% 、 0.4 \%$ 和 $0.7 \%$ (表 7 ). 就整个枢纽调度的低枯水期而言, 外 排径流总量增加了 $2.1 \%$,约占长江大通同期径流总量的 $0.5 \%$.

有枢纽情景尽管导致了不同调度时段湖泊外排水量的减小或增加, 但就一个完整的调度时期而言, 湖 泊外排水量变化不大,其值为 $-0.3 \%$,也即水量基本保持平衡 (表 7 ).

\section{2 平水年型的影响}

平水年型丰水期的典型年份是 2009 年. 2009 年 9- 10 月的最高水位不足 $15 \mathrm{~m}$ (图 6a), 低于该时期枢 
表 $72002-2003$ 年枢纽工程不同调度时段有枢纽与无枢纽径流总量及其变化和与大通同期总量占比*

Tab.7 Runoff and its changes of the lake in the scenario with/without the Poyang Lake Hydraulic

Project under different regulation periods from 2002 to 2003 and the proportion of the runoff in the same period of the Yangtze River Datong Hydrological Station

\begin{tabular}{ccccccc}
\hline 调度时段 & 时间 & $\begin{array}{c}\text { 无枢纽径流 } \\
\text { 总量 } /\left(\times 10^{8} \mathrm{~m}^{3}\right)\end{array}$ & $\begin{array}{c}\text { 有枢纽径流 } \\
\text { 总量 } /\left(\times 10^{8} \mathrm{~m}^{3}\right)\end{array}$ & $\begin{array}{c}\text { 绝对变化/ } \\
\left(\times 10^{8} \mathrm{~m}^{3}\right)\end{array}$ & $\begin{array}{c}\text { 相对变化/ } \\
\%\end{array}$ & $\begin{array}{c}\text { 与大通同期 } \\
\text { 总量占比 } / \%\end{array}$ \\
\hline 江湖连通期 & $2002 / 3 / 26-2002 / 8 / 31$ & 1015.62 & 1014.61 & -1.01 & -0.1 & -0.02 \\
枢纽蓄水期 & $2002 / 9 / 1-2002 / 9 / 15$ & 151.44 & 150.54 & -0.90 & -0.6 & -0.1 \\
三峡水库蓄水期 & $2002 / 9 / 16-2002 / 10 / 10$ & 196.18 & 178.76 & -17.42 & $-8.9(-0.7)$ & -2.5 \\
& $2002 / 10 / 11-2002 / 10 / 31$ & 77.38 & 92.93 & 15.55 & 20.1 & 3.8 \\
补偿调节期 & $2002 / 11 / 1-2003 / 1 / 10$ & 351.38 & 344.05 & -7.33 & -2.1 & -0.6 \\
低枯水期 & $2003 / 1 / 11-2003 / 2 / 10$ & 108.99 & 111.57 & 2.58 & $2.4(2.1)$ & 0.6 \\
& $2003 / 2 / 11-2003 / 3 / 10$ & 129.07 & 130.77 & 1.70 & 1.3 & 0.4 \\
& $2003 / 3 / 11-2003 / 3 / 25$ & 74.64 & 76.77 & 2.13 & 2.9 & 0.7 \\
整个调度时期 & $2002 / 9 / 1-2003 / 3 / 25$ & 1089.08 & 1085.39 & -3.68 & -0.3 & -0.1 \\
\hline
\end{tabular}

* 括号内数据为该调度时段的总体相对变化,下同.

纽调度的最高水位. 9 月份有枢纽情景下出现了负流量, 而在无枢纽状态下并无这种现象出现 (图 6b). 其原 因可以理解为在实际水位不足 $15 \mathrm{~m}$, 且人湖流量无法满足将水位调度到 $15 \mathrm{~m}$ 的情况下, 模型由于水位强迫 造成了系统外的补水现象. 9 月 1 日-9 月 15 日的枢纽蓄水期,有枢纽与无枢纽相比湖泊外排水量减少了 $111.9 \%$ (表 8), 这就意味着即使完全截流使湖泊外排水量为 0 , 要达到 $15 \mathrm{~m}$ 的调度水位, 尚缺 $11.9 \%$ 的水 量, 按照无枢纽状态下的日流量估算, 须到 9 月 17 日才能实现; 如按无枢纽时流量的一半来估计, 即需到 10 月 21 日才能将水位调度到 $15 \mathrm{~m}$.

9 月 16 日-10月 10 日,枢纽调度处于三峡水库蓄水期时段. 有、无枢纽相比, 湖泊外排径流总量增加了 $52.5 \%$, 与大通同期总量占比为 $7.4 \%$. 由于该增加值包含了因水位强迫导致的系统外补水量, 扣除这一部分 水量,实际增量应为 $42.6 \%$, 该增量占大通水文站同期径流总量的 $6.0 \%$; 而在 10 月 11 日- 10 月 31 日期间的 三峡水库蓄水期时段,有、无枢纽相比, 湖泊外排径流总量则增加了 79.7\% , 占大通同期总量的 $6.5 \%$ (表 8 ).
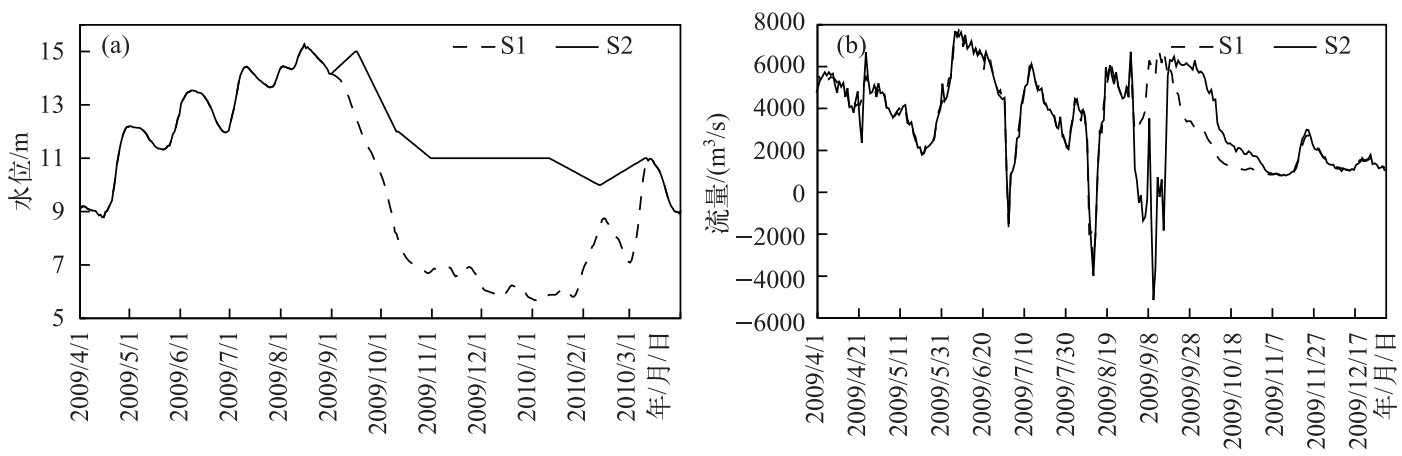

图 62009 年无枢纽 (S1) 与有枢纽 (S2) 情景下的水位 (a) 和相应的逐日流量 (b)

Fig.6 Water levels (a) and flow hydrographs (b) of the lake in the scenarios with (S2) and without (S1) the Poyang Lake Hydraulic Project in 2009

平水年型枯水期的典型年份为 2001 年. 2001 年 11 月 1 日一-2002 年 1 月 10 日期间,有、无枢纽相比,外 排径流总量减少了 3.0\% (表 9), 这从图 7 的水位过程线中可以得到解释. 1 月 11 日-3 月 25 日的整个低枯 水期, 有、无枢纽相比, 外排径流总量增加了 $7.8 \%$, 表明在鄱阳湖和长江都处于低水位时, 枢纽工程的调度方 案对长江具有补偿作用. 但从低枯水期包含的 3 个过程来看, 不同过程的增减水作用不同. 1 月 11 日 -2 月 
10 日的调度水位下降过程导致外排径流总量增加了 $10.9 \%$, 该增量占大通水文站同期总量的 $2.3 \%$.

表 82009 年丰水期不同调度阶段有/无枢纽状态下径流总量及其变化和与大通同期总量占比

Tab.8 Runoff and its changes of the lake in the scenarios with/without the Poyang Lake Hydraulic

Project under different regulation periods of the wet season in 2009 and the proportion of the runoff in the same period of the Yangtze River Datong Hydrological Station

\begin{tabular}{|c|c|c|c|c|c|c|}
\hline 调度时段 & 时间 & $\begin{array}{c}\text { 无枢纽径流 } \\
\text { 总量 } /\left(\times 10^{8} \mathrm{~m}^{3}\right)\end{array}$ & $\begin{array}{c}\text { 有枢纽径流 } \\
\text { 总量/ }\left(\times 10^{8} \mathrm{~m}^{3}\right)\end{array}$ & $\begin{array}{l}\text { 绝对变化/ } \\
\left(\times 10^{8} \mathrm{~m}^{3}\right)\end{array}$ & $\begin{array}{c}\text { 相对变化/ } \\
\%\end{array}$ & $\begin{array}{l}\text { 与大通同期 } \\
\text { 总量占比 } / \%\end{array}$ \\
\hline 江湖连通期 & $2009 / 3 / 26-2009 / 8 / 31$ & 586.83 & 588.68 & 1.86 & 0.3 & 0.04 \\
\hline 枢纽蓄水期 & $2009 / 9 / 1-2009 / 9 / 15$ & 65.47 & -7.77 & -73.24 & -111.9 & -15.4 \\
\hline \multirow[t]{2}{*}{ 三峡水库蓄水期 } & $2009 / 9 / 16-2009 / 10 / 10$ & 78.85 & 120.21 & 41.36 & 52.5 & 7.4 \\
\hline & $2009 / 10 / 11-2009 / 10 / 31$ & 22.07 & 39.65 & 17.58 & 79.7 & 6.5 \\
\hline 整个调度时期 & $2009 / 9 / 1-2010 / 3 / 25$ & 542.71 & 538.68 & -4.03 & -0.7 & -0.1 \\
\hline
\end{tabular}

2 月 11 日至 3 月 10 日的调度水位提升过程,使湖泊外排水量减少了 $7.3 \%$,约占长江大通水文站同期径 流总量的 $1.2 \%$; 而 3 月 11 日-3 月 25 日由调度水位到自然状态水位的过渡过程则导致了外排水量增加了 $24.1 \%$, 约占大通同期径流总量的 $3.3 \%$. 由此可以看出, 平水年型低枯水期枢纽水位调度对长江干流径流总 量的影响,无论是增加还是减小,所占比例均不大,但却明显大于丰水年型.

表 $92001-2002$ 年枯水期不同调度阶段有/无枢纽状态下径流总量及其变化和与大通同期总量占比

Tab.9 Runoff and its changes of the lake in the scenarios with/without the Poyang Lake Hydraulic Project under different regulation periods of the dry season from 2001 to 2002 and the proportion

of the runoff in the same period of the Yangtze River Datong Hydrological Station

\begin{tabular}{ccccccc}
\hline 调度时段 & 时间 & $\begin{array}{c}\text { 无枢纽径流 } \\
\text { 总量 } /\left(\times 10^{8} \mathrm{~m}^{3}\right)\end{array}$ & $\begin{array}{c}\text { 有枢纽径流 } \\
\text { 总量 } /\left(\times 10^{8} \mathrm{~m}^{3}\right)\end{array}$ & $\begin{array}{c}\text { 绝对变化/ } \\
\left(\times 10^{8} \mathrm{~m}^{3}\right)\end{array}$ & $\begin{array}{c}\text { 相对变化/ } \\
\%\end{array}$ & $\begin{array}{c}\text { 与大通同期 } \\
\text { 总量占比 } / \%\end{array}$ \\
\hline 江湖连通期 & $2001 / 3 / 26-2001 / 8 / 31$ & 920.93 & 922.20 & 1.27 & 0.1 & 0.03 \\
补偿调节期 & $2001 / 11 / 1-2002 / 1 / 10$ & 142.25 & 137.95 & -4.30 & -3.0 & -0.4 \\
低枯水期 & $2002 / 1 / 11-2002 / 2 / 10$ & 56.08 & 62.20 & 6.11 & $10.9(7.8)$ & 2.3 \\
& $2002 / 2 / 11-2002 / 3 / 10$ & 47.51 & 44.06 & -3.46 & -7.3 & -1.2 \\
& $2002 / 3 / 11-2002 / 3 / 25$ & 33.50 & 41.58 & 8.08 & 24.1 & 3.3 \\
整个调度时期 & $2001 / 9 / 1-2002 / 3 / 25$ & 1372.52 & 1370.01 & -2.51 & -0.2 & -0.1 \\
\hline
\end{tabular}
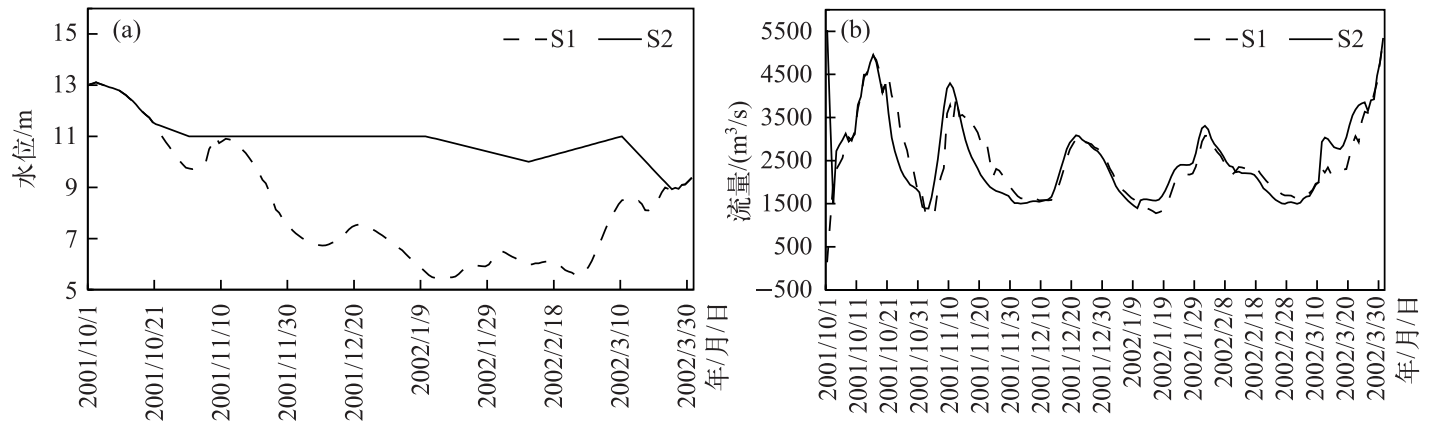

图 7 2001-2002 年枯水期无枢纽 (S1) 与有枢纽 (S2) 情景下的水位 (a) 和相应的逐日流量 (b)

Fig.7 Water levels (a) and flow hydrographs (b) of the lake in the scenarios with (S2) and without (S1) the Poyang Lake Hydraulic Project under the dry season from 2001 to 2002 


\section{3 枯水年型的影响}

枯水年型丰水期的典型年份为 2006 年. 2006 年 9 月 1 日的实际水位不足 $9 \mathrm{~m}$ ( 图 8a), 由于实际水量明 显不足, 模型在水位强迫下导致从系统外补水, 9 月 6 日起平均流量由 0 转为负值, 至 9 月 11 日负值达最大 $\left(-12479.5 \mathrm{~m}^{3} / \mathrm{s}\right.$, 图 8b). 该时段湖泊外排水量减少了 $293.4 \%$ (表 10$)$,亦即该时段如果完全截流使外排水量 为 0 的话,要达到调度水位的 $15 \mathrm{~m}$, 仍尚缺 $66.23 \times 10^{8} \mathrm{~m}^{3}$ 水量 (占该时段无枢纽状态时径流总量的 $139.4 \%$ ), 该水量如以无枢纽状态下的逐日流量来大致估算的话,则需到 10 月 25 日才能满足, 如果外排不完全截流, 而是以无枢纽状态时的 $1 / 3$ 流量来估算的话, 则需到 11 月 24 日才能满足这个水量余缺, 这将让处于三峡水 库蓄水期的长江失去了鄱阳湖的来水, 无法实现枢纽调度方案在三峡水库蓄水期对长江进行补水的作用. 这说明在丰水期水位严重偏低的枯水年份,枢纽工程的水位调度方案存在一定的不合理性.
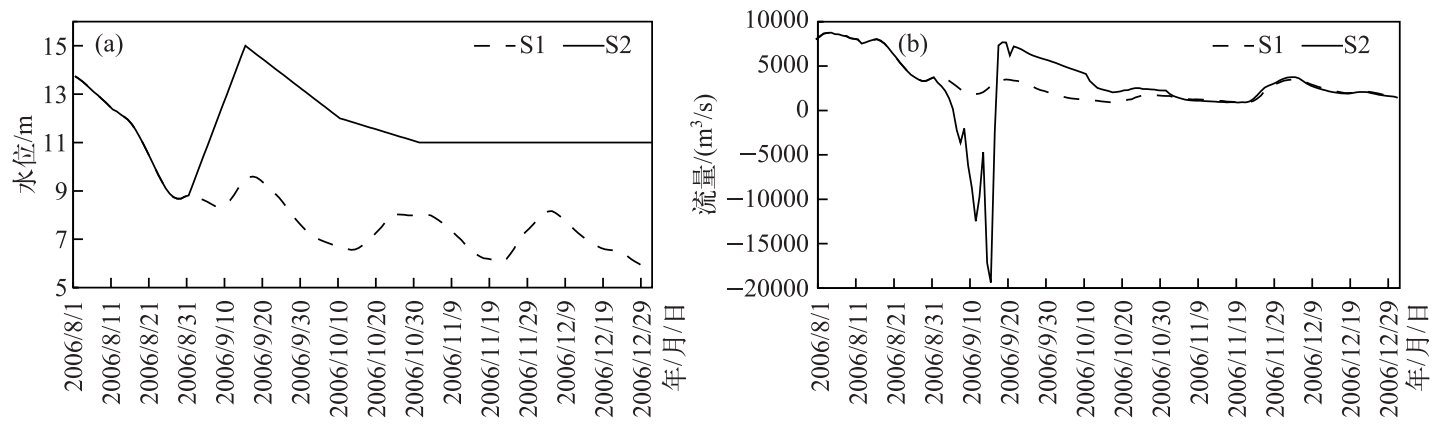

图 82006 年 8-12 月无枢纽 (S1) 与有枢纽 (S2) 情景下的水位 (a) 和相应的逐日流量 (b)

Fig.8 Water levels (a) and flow hydrographs (b) of the lake in the scenarios with (S2) and without (S1) the Poyang Lake Hydraulic Project from August to December in 2006

表 102006 年丰水期不同调度阶段有/无枢纽状态下径流总量及其变化和与大通同期总量占比

Tab.10 Runoff and its changes of the lake in the scenarios with/without the Poyang Lake Hydraulic Project under different regulation periods of the wet season in 2006 and the proportion of the runoff in the same period of the Yangtze River Datong Hydrological Station

\begin{tabular}{ccccccc}
\hline 调度时段 & 时间 & $\begin{array}{c}\text { 无枢纽径流 } \\
\text { 总量 } /\left(\times 10^{8} \mathrm{~m}^{3}\right)\end{array}$ & $\begin{array}{c}\text { 有枢纽径流 } \\
\text { 总量 } /\left(\times 10^{8} \mathrm{~m}^{3}\right)\end{array}$ & $\begin{array}{c}\text { 绝对变化/ } \\
\left(\times 10^{8} \mathrm{~m}^{3}\right)\end{array}$ & $\begin{array}{c}\text { 相对变化/ } \\
\%\end{array}$ & $\begin{array}{c}\text { 与大通同期 } \\
\text { 总量占比 } / \%\end{array}$ \\
\hline 江湖连通期 & $2006 / 3 / 26-2006 / 8 / 31$ & 1142.41 & 1143.21 & 0.80 & 0.07 & 0.02 \\
枢纽蓄水期 & $2006 / 9 / 1-2006 / 9 / 15$ & 34.25 & -66.23 & -100.48 & $-293.4^{*}$ & -41.2 \\
三峡水库蓄水期 & $2006 / 9 / 16-2006 / 10 / 10$ & 51.14 & 119.45 & 68.32 & $133.6^{*}\left(117.4^{*}\right)$ & 18.5 \\
& $2006 / 10 / 11-2006 / 10 / 31$ & 23.83 & 43.45 & 19.62 & $82.3^{*}$ & 7.1 \\
整个调度时期 & $2006 / 9 / 1-2007 / 3 / 25$ & 369.13 & 367.29 & -1.85 & -0.5 & -0.1 \\
\hline
\end{tabular}

*表示因系统外补水现象发生,该数据存在一定的不合理性.

枯水年型枯水期的典型年份是 2003 年. 从图 9 和表 11 可以看出, 2003 年 11 月 1 日- 2004 年 1 月 10 日的补偿调节期, 调度水位稳定在 $11 \mathrm{~m}$, 这种状态导致了有枢纽情景的外排水量减少了 $9.7 \%$, 该减量约占 长江大通水文站同期径流总量的 $0.8 \%$. 低枯水期的 3 个调度时段除了 2 月 $11-3$ 月 10 日调度水位由 $11 \mathrm{~m}$ 降至 $10 \mathrm{~m}$ 的时段有 $4.7 \%$ 减排之外 (约占长江大通水文站同期流量的 $0.7 \%$ ), 其余两个时段均导致外排水量 有所增加, 这种趋势与丰水年型、平水年型的变化一致, 且增幅明显大于其他 2 种年型, 其中低枯水期的 1 月 11 日-2 月 10 日,外排水量增加了 $38.9 \%$, 而由调度水位转换到自然水位的过程也使有枢纽情景外排水量 增加了 $31.0 \%$, 其增加量与大通水文站同期流量的占比分别为 $2.7 \%$ 和 $2.9 \%$; 整个低枯水期的外排水量增加 比例为 $17.0 \%$. 

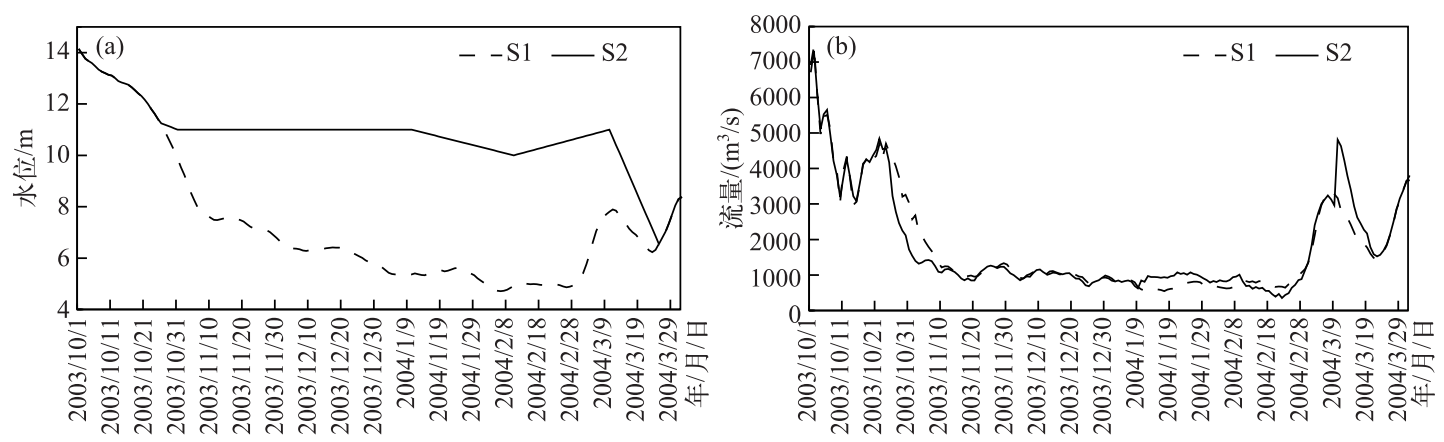

图 92003 年 10 月 -2004 年 3 月无枢纽 (S1) 与有枢纽 (S2) 情景下的水位 (a) 和相应的逐日流量 (b)

Fig.9 Water levels (a) and flow hydrographs (b) of the lake in the scenarios with (S2) and without (S1) Poyang Lake Hydraulic Project from October, 2003 to March, 2004

表 11 2003-2004 年枯水期不同调度阶段有/无枢纽状态下径流总量及其变化和与大通同期总量占比

Tab.11 Runoff and its changes of the lake in the scenarios with/without Poyang Lake Hydraulic Project under different regulation periods of the dry season during 2003-2004 and the proportion of the runoff in the same period of the Yangtze River Datong Hydrological Station

\begin{tabular}{ccccccc}
\hline 调度时段 & 时间 & $\begin{array}{c}\text { 无枢纽径流 } \\
\text { 总量 } /\left(\times 10^{8} \mathrm{~m}^{3}\right)\end{array}$ & $\begin{array}{c}\text { 有枢纽径流 } \\
\text { 总量 } /\left(\times 10^{8} \mathrm{~m}^{3}\right)\end{array}$ & $\begin{array}{c}\text { 绝对变化/ } \\
\left(\times 10^{8} \mathrm{~m}^{3}\right)\end{array}$ & $\begin{array}{c}\text { 相对变化/ } \\
\%\end{array}$ & $\begin{array}{c}\text { 与大通同期 } \\
\text { 总量占比/\% }\end{array}$ \\
\hline 江湖连通期 & $2003 / 3 / 26-2003 / 8 / 31$ & 747.62 & 746.59 & -1.03 & -0.1 & -0.02 \\
补偿调节期 & $2003 / 11 / 1-2004 / 1 / 10$ & 69.48 & 62.76 & -6.72 & -9.7 & -0.8 \\
低枯水期 & $2004 / 1 / 11-2004 / 2 / 10$ & 17.95 & 24.93 & 6.98 & $38.9(17.0)$ & 2.7 \\
& $2004 / 2 / 11-2004 / 3 / 10$ & 36.66 & 34.95 & -1.71 & -4.7 & -0.7 \\
& $2004 / 3 / 11-2004 / 3 / 25$ & 28.59 & 37.44 & 8.85 & 31.0 & 2.9 \\
整个调度时期 & $2003 / 9 / 1-2004 / 3 / 25$ & 276.80 & 276.31 & -0.50 & -0.2 & -0.01 \\
\hline
\end{tabular}

\section{5 结论与讨论}

本文通过设置丰、平、枯 3 种水文年型, 在数值模拟的基础上, 就拟建的鄱阳湖水利枢纽工程调度方案 对长江干流流量可能造成的影响进行了探讨. 分析了 3 种年型枢纽工程不同调度时段无/有枢纽情景下湖 泊外排长江干流的流量变化及其对长江干流的影响. 通过分析得到以下几点初步结论:

1) 在一个鄱阳湖水利枢纽工程水位调度周期中,无/有枢纽情景下湖泊外排到长江干流的径流总量差 异很小, 基本维持了无枢纽状态/有枢纽情景下的水量平衡, 但在一定程度上改变了湖泊外排长江干流水量 的分配时间,使不同年型丰水期的湖泊外排水量有所减少, 而在长江低枯水期, 对长江流量则有一定的增排 作用,且增排效果枯水年型>平水年型>丰水年型.

2) 主要增排过程出现在 1 月 11 日-2 月 10 日调度水位的提升过程和 3 月 11 日-3 月 25 日调度水位 向自然水位过渡过程, 从模拟的 3 种年型来看,这两个过程增排最大的近 40\%;但 2 月 11 日 - 3 月 10 日的 枢纽调度水位抬升过程, 使外排到长江干流的水量有所减少, 但不同年型的减少量有所不同, 其中外排减少 量最大的为 $7.3 \%$, 约占长江大通同期流量的 $1.2 \%$.

3 ) 在丰水期湖泊水位偏低且枢纽位置的实际水位严重不足 $9 \mathrm{~m}$ 的年型情况下, 按照枢纽工程的水位调 度方案要在 9 月 15 日将湖泊水位提升至 $14 \sim 15 \mathrm{~m}$ 是难于实现的, 现有的枢纽工程调度方案在这种情况下 缺乏可操作性,有进一步细化和优化的空间.

4) 由于受 EFDC 基础模型的限制, 无枢纽状态的下边界设置在湖口, 而有枢纽情景的下边界只能设置 在枢纽工程的位置, 从而导致了无枢纽与有枢纽模拟的下边界不一致, 且在整个流量分析过程中, 由于受有 
枢纽下边界位置的影响, 无论是无枢纽还是有枢纽, 流量数据均采自枢纽断面, 与长江还有一定距离. 因此 本文在讨论枢纽工程对长江流量的影响时,存在一定的不合理和一定的模拟误差.

\section{6 参考文献}

[ 1 ] Yu Qihui, Ma Qiang, You Zhongqiong et al. Impact of regulation of Poyang Lake water conservancy project on lake water level and flow velocity in dry seasons. Yangtze River, 2013, 44(17):18-21,59. [余启辉, 马强, 游中琼等. 鄱阳湖水利 枢纽调度对湖区枯期水位与流速影响. 人民长江, 2013, 44(17) : 18-21,59.]

[ 2 ] Wang Peng, Lai Geying, Huang Xiaolan. Simulation of the impact of Lake Poyang Project on the dynamic of lake water level. J Lake Sci, 2014, 26 (1) :29-36. DOI : 10.18307/2014.0104. [王鹏, 赖格英, 黄小兰. 鄱阳湖水利枢纽工程对 湖泊水位变化影响的模拟. 湖泊科学, 2014, 26(1) : 29-36.]

[ 3 ] Wang P, Lai GY, Li L. Predicting the hydrological impacts of the Poyang Lake Project using an EFDC Model. Journal of Hydrologic Engineering, 2015, 20(12) : 05015009-1-10.

[ 4 ] Lai Geying, Huang Xiaolan, Wang Peng et al. A simulation research of impacts of the Lake Poyang hydraulic project on hydrology and hydrodynamics. J Lake Sci, 2015, 27(1) : 128-140. DOI:10.18307/2015.0116. [赖格英, 黄小兰, 王鹏 等. 鄱阳湖水利枢纽工程对鄱阳湖水文水动力影响的模拟. 湖泊科学, 2015, 27(1): 128-140.]

[ 5 ] Lai GY, Wang P, Li L. Possible impacts of the Poyang lake (China) hydraulic project on lake hydrology and hydrodynamics. Hydrology Research, 2016. DOI: 10.2166/nh.2016.174.

[ 6 ] Du Yanliang, Zhou Huaidong, Mao Zhanpo et al. Modeling the impacts of Poyang Lake Water Control Project on hydrodynamics and water quality. Journal of China Institute of Water Resources and Hydropower Research, 2011, 9(4) : 249-258. [杜彦良, 周怀东, 毛战坡等. 鄱阳湖水利枢纽工程对水质环境影响研究. 中国水利水电科学研究院学报, 2011,9 (4) : 249-258.]

[ 7 ] Du Yanliang, Zhou Huaidong, Peng Wenqi et al. Modeling the impacts of the change of river-lake relationship on the hydrodynamic and water quality revolution in Poyang Lake. Acta Scientiae Circumstantiae, 2015, 35(5) : 1274-1284. [杜彦 良, 周怀东, 彭文启等. 近 10 年流域江湖关系变化作用下鄱阳湖水动力及水质特征模拟. 环境科学学报, 2015, 35(5) : 1274-1284.]

[ 8 ] Zhang Shuanghu, Jiang Yunzhong, Liu Xiaozhi et al. Study on dispatching scheme of Water Control Project in Poyang Lake and its influence on water resources and flood control. Journal of China Institute of Water Resources and Hydropower Research, 2011,9(4) : 257-261. [ 张双虎, 蒋云钟, 刘晓志等. 鄱阳湖水利枢纽运行调度方式及其对水资源与防洪 的影响. 中国水利水电科学研究院学报, 2011, 9(4): 257-261.]

[ 9 ] Tan Guoliang, Guo Shenglian, Wang Jun et al eds. Study on the evolution of hydrology and water resources in Poyang Lake Ecological Economic Zone. Beijing: China Water \& Power Press, 2013. [谭国良, 郭生练, 王俊等. 鄱阳湖生态经济区 水文水资源演变规律研究. 北京: 中国水利水电出版社, 2013.]

[10] Zhang Q, Ye X, Werner AD et al. An investigation of enhanced recessions in Poyang Lake: Comparison of Yangtze River and local catchment impacts. J Hydrol, 2014, 517: 425-434.

[11] Zhang Erfeng, Chen Xiqing. Changes of water discharge between Datong and the Changjiang Estuary during the dry season. Acta Geographica Sinica, 2003, 58(2): 231-238. [张二凤, 陈西庆. 长江大通-河口段枯季的径流量变化. 地理学 报, 2003, 58(2): 231-238.]

[12] Hamrick JM. A three-dimensional environmental fluid dynamics computer code: Theoretical and computational aspects. The College of William and Mary, Virginia Institute of Marine Science, Special Report 317, 1992.

[13] Hu Chunhua, Shi Wei, Hu Longfei et al. Simulation study on the impact of Poyang Lake hydro-junction projects on nitrogen and phosphorus nutrient in lake region. Resources and Environment in the Yangtze Basin, 2012, 21(6) : 749-755. [胡 春华, 施伟, 胡龙飞等. 鄱阳湖水利枢纽工程对湖区氮磷营养盐影响的模拟研究. 长江流域资源与环境, 2012,21 (6) : 749-755.]

[14] Feng L, Hu CM, Chen XL et al. Satellite observations make it possible to estimate Poyang Lake's water budget. Environmental Research Letters, 2011, 6: 044023.

[15] Krausel P, Boyle DP, Base F. Comparison of different efficiency criteria for hydrological model assessment. Advances in Geosciences, 2005, 5: 89-97. 